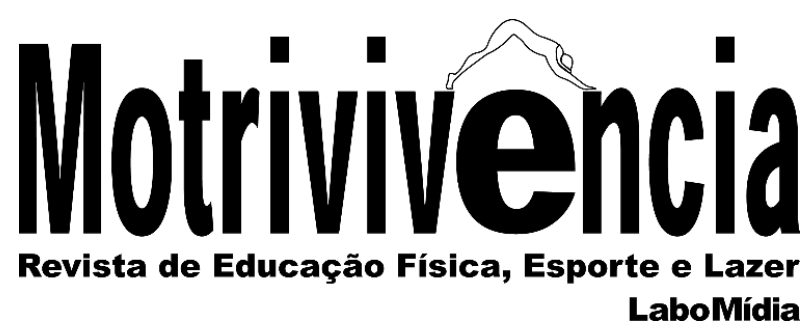

\title{
Corpos secos ou molhados? Representações do suor em duas academias de ginástica do Rio de Janeiro, Brasil
}

\section{RESUMO}

Embora "suar a camisa" seja uma expressão êmica comum no âmbito das práticas corporais, pouco se têm explorado simbolicamente tal discurso na área de Educação Física. Assim, o objetivo deste trabalho foi compreender em que medida as representações dos praticantes de musculação em academias de ginástica acerca do suor os influenciavam nos seus anseios para o corpo. Pautada pela abordagem antropológica, durante um ano, uma etnografia comparativa foi realizada em duas academias inseridas em contextos socioeconômicos e culturais distintos do Rio de Janeiro. Concluiu-se que a multiplicidade de significados atribuídos ao suor pelos alunos influenciava o engajamento dos mesmos no ato de se exercitar.

PALAVRAS-CHAVE: Suor; Secreções corporais; Academias de ginástica; Etnografia; Educação física e treinamento
Alan Camargo Silva

Doutor em Saúde Coletiva

Universidade Federal do Rio de Janeiro -

UFRJ

Escola de Educação Física e Desportos

Rio de Janeiro, Rio de Janeiro, Brasil

alan10@zipmail.com.br

http://orcid.org/0000-0003-1729-5151

Jaqueline Ferreira

Doutora em Antropologia Social

Universidade Federal do Rio de Janeiro -

UFRJ

Instituto de Estudos em Saúde Coletiva

Rio de Janeiro, Rio de Janeiro, Brasil jaquetf@gmail.com

https://orcid.org/0000-0002-7662-1773 


\title{
Dried or wet bodies? Representations of sweat in two fitness centers in Rio de Janeiro, Brazil
}

\begin{abstract}
Although work hard with the sweat in the shirt presents an ordinary emic expression related to the corporal practices, it is possible to note a little number of investigations that the objective is to explore this conception, symbolically, in the Physical Education. The objective of the study is to understand the representations of some practitioners, emphasizing if there is any relationship between the sweat and their expectations toward the body in some Fitness Centers. The research is a comparative ethnography done in two different (in the social, economic and cultural aspects) Fitness Centers in Rio de Janeiro, during one year. The results show that the multiplicity of meanings related to the sweat by the students had a connection between the engagement and their exercise.
\end{abstract}

KEYWORDS: Sweat; Bodily secretions; Fitness centers; Ethnography; Physical education and training

\section{Cuerpos secos o mojados? Representaciones del sudor en dos centros de acondicionamiento de Rio de Janeiro, Brasil}

\section{RESUMEN}

Aunque sudar la camisa sea una expresión común en el ámbito de las prácticas corporales, pocos estudios exploran simbólicamente ese discurso en la Educación Física. El trabajo tuvo como objetivo comprender de qué manera las representaciones de los practicantes de musculación en Centros de Acondicionamiento tocantes al sudor influenciaban sus deseos para el cuerpo. Pautado por una perspectiva antropológica, se realizó, durante un año, una etnografía comparativa en dos Centros de Acondicionamiento pertenecientes a contextos sociales, económicos y culturales distintos de la ciudad de Rio de Janeiro. Se concluyó que la multiplicidad de significados corporales atribuidos al sudor por los alumnos influenciaba su comprometimiento en el acto ejercitarse.

PALABRAS-CLAVE: Sudor; Secreciones corporales; Centros de acondicionamiento; Etnografía; Educación y entrenamiento físico 


\section{CONSIDERAÇÕES INICIAIS}

O presente estudo parte da ideia de que os sentidos e os significados atribuídos ao corpo podem variar de acordo com o contexto sociocultural (LE BRETON, 2016). Assim, este trabalho se refere às relações, representações, crenças, percepções e opiniões acerca do suor em duas academias de ginástica no Rio de Janeiro.

Geralmente, os resíduos corporais podem ser considerados elementos de perigo, uma vez que, pela sua saída dos "limites" do corpo, a noção de fora do lugar tende ameaçar a ordem das coisas (DOUGLAS, 1991; HELMAN, 1994). Tais fatos são interessantes na medida em que “[...] o corpo é 'bom para pensar' a dualidade da estrutura social, exprimindo no que é corporalmente 'puro' e ‘impuro' respectivamente o que a sociedade quer e não quer ser” (RODRIGUES, 2006, p.149).

Nesse contexto, é imperioso conhecer os "limites" do suor construídos pelos alunos na musculação em academias cariocas na medida em que tal secreção corporal pode demonstrar os diferentes usos do corpo desses frequentadores durante os exercícios físicos. Ademais, os diversos sentidos e significados atribuídos ao suor pelos alunos indicam uma gama extensa de pensamentos e de comportamentos referentes ao que desejam para si durante as práticas corporais, elementos estes que podem ser fundamentais para se pensar a intervenção dos profissionais de Educação Física. Para Silva (2017, p.51), “[...] há cada vez mais a necessidade de articular os conhecimentos anatomofisiológicos e do treinamento com normas, costumes, crenças e valores que são determinantes nas maneiras como cada grupo social se engaja nas práticas corporais".

Desse modo, o objetivo deste estudo foi compreender em que medida as representações dos praticantes de musculação em academias de ginástica acerca do suor os influenciavam nos seus anseios para o corpo. Os dados se referem a uma etnografia mais ampla sobre as representações acerca dos "limites" corporais e noções de risco em duas academias de ginástica cariocas (SILVA, $2014)^{1}$.

\section{PROCEDIMENTOS METODOLÓGICOS}

A presente pesquisa de cunho qualitativo busca desvelar, em parte, os significados das coisas que são construídos e reconstruídos de modo ininterrupto por dado grupo social em determinado contexto sociocultural (MINAYO, 2010). Portanto, este trabalho foca, de forma

\footnotetext{
${ }^{1}$ Declaramos que este estudo não possui conflito de interesses.
} 
comparativa, nas múltiplas concepções dos alunos de duas academias de ginástica acerca do suor e suas relações com os seus desejos corporais.

Sobre o universo empírico, um critério delimitador para a escolha das academias cariocas foi buscar estabelecimentos caracterizados de pequeno (P) e de grande porte $(\mathrm{G})$, conforme a classificação de Bertevello (2006). Enquanto nas pequenas academias tendem a uma administração mais familiar e de menor alcance no que diz respeito à ampliação da empresa, nas grandes academias, notam-se tecnologias e teorias administrativas mais avançadas do mercado (FURTADO, 2009). Alguns estudos comparativos, como o de Hansen e Vaz (2006) e Sassatelli (2000), conseguiram identificar peculiaridades nos significados atribuídos ao corpo em relação ao porte da academia. Após uma busca por academias desses portes, o pesquisador optou por duas das quais atendiam essas características. Vale registrar que as academias $\mathrm{P}$ e $\mathrm{G}$ foram selecionadas dentre outras na cidade em função das suas proximidades dos locais de trabalho e de residência do pesquisador. Esta seleção ancora-se na premissa básica de Malinowski (1986) que providenciar condições adequadas para o trabalho de campo se caracteriza pelo passo mais elementar de uma etnografia.

Outro critério delimitador para a escolha das academias se referiu ao local que foi privilegiado no estudo: um bairro de baixo e outro de alto poder aquisitivo da cidade do Rio de Janeiro, respectivamente, onde se localizam a academia P, na Cidade de Deus (CDD), e G, na Barra da Tijuca (Barra). De acordo com Boltanski (2004) e Bourdieu (1983), os ambientes das camadas sociais podem se diferenciar quanto aos usos simbólicos do corpo, permitindo, assim, estabelecer comparações ao abranger um universo amplo de sujeitos de pesquisa. Malysse (2007) chega a apontar que a diversidade de camadas sociais no Rio de Janeiro possibilita enxergar distintos contextos "estético-sociais".

A infraestrutura da academia P era constituída por um "pequeno prédio" de dois andares próximo à favela local e dividia espaço com um self service. No primeiro andar, havia espaços para aulas de danças ou ginástica e lutas e o segundo andar continha os aparelhos de musculação e aproximadamente dez aparelhos ergométricos. Ali havia mofo, infiltrações, pichações. Os espaços eram estreitos e mal iluminados onde também era possível visualizar a tubulação hidráulica e a fiação elétrica expostas, além de vergalhões enferrujados ao longo da estrutura do telhado de amianto. Esta academia operava basicamente com um funcionário "multiuso" e uma recepcionista sem carteira assinada.

Já a academia G ocupava grande parte do espaço de um shopping center e era considerada a maior unidade de uma filial de rede de academias do Rio de Janeiro. Possuía aproximadamente dez vezes o número de aparelhos de musculação da academia $\mathrm{P}$ e setenta aparelhos ergométricos de 
marca. Ao entrar, era possível sentir que estava no interior de um clube em que havia todos os tipos de serviços (personal trainer, reavaliação funcional, aluguel de armários e toalhas, rouparia, clínica de fisioterapia e consultório de nutrição, serviços de spa, massagem e meditação), além de modalidades de práticas corporais e esportivas (atividades aquáticas, aulas coletivas, esportes, lutas, danças, etc.). Este estabelecimento não somente possuía cerca de cem empregados periodicamente vinculados a programas de treinamento profissional, como também terceirizava serviços de manutenção e limpeza.

A etnografia comparativa teve duração de um ano, entre Julho/2012 a Julho/2013, tendo sido a observação participante realizada durante doze meses no setor da musculação da academia P e dez meses na academia G. O recorte etnográfico apresentado aqui se refere à observação participante voltada às interações sociais cotidianas dos alunos de ambos os sexos entre quinze a cinquenta anos de ambas as academias. Os frequentadores da academia $\mathrm{P}$ eram de cor negra ou parda, possuíam renda mensal entre um a três salários mínimos e grau de escolaridade, em sua maioria, de ensino fundamental incompleto. Já os frequentadores da academia $\mathrm{G}$ eram predominantemente de cor branca, ganhavam na faixa entre cinco a vinte salários mínimos e possuíam ensino superior completo. Com base no setor administrativo de cada estabelecimento, na academia P, havia cerca de duzentos alunos com matrículas ativas que pagavam uma mensalidade de $\mathrm{R} \$ 55,00$ e na academia $\mathrm{G}$, três mil alunos que pagavam em torno de R\$ 500,00. Durante o trabalho de campo do pesquisador em ambas as academias, foi possível observar um maior número de homens do que mulheres circulando pelo setor na musculação, embora na academia G, por vezes, essa proporção não fosse tão clara em função dos inúmeros contatos mistos que havia ali.

Foram elaborados dois diários de campo, um para cada estabelecimento, com o intuito de registrar as situações e práticas sociais vivenciadas e observadas pelo pesquisador no trabalho de campo, que durava, em média, quatro horas por duas vezes na semana, majoritariamente, no período tarde/noite, entre as dezessete às vinte e uma horas. De acordo com DaMatta (2010, p.219), é no diário de campo em que “[...] pesquisador deverá anotar tudo o que lhe acontecer no decorrer do dia. Frases soltas, comportamentos curiosos, técnicas de corpo desconhecidas e acontecimentos imprevistos, mesmo sendo ininteligíveis [...]".

Esta pesquisa foi aprovada e autorizada pelo Comitê de Ética em Pesquisa do Instituto de Estudos em Saúde Coletiva da Universidade Federal do Rio de Janeiro (CAAE: 01559712.7.0000.5286 / Número do parecer: 203.235)².

\footnotetext{
${ }^{2}$ Foram utilizados nomes fictícios com o intuito de garantir o anonimato dos participantes do estudo.
} 


\section{APRESENTAÇÃO E DISCUSSÃO DOS ACHADOS}

Levando em conta que as identidades corporais dos sujeitos no cenário urbano são propícias a múltiplas, híbridas e complexas formas de si (VELHO, 2009), destaca-se que em cada grupo social são distintas as ênfases na atenção dada a determinados órgãos dos sentidos (ROCHA; RODRIGUES, s/d). Assim, partindo da premissa de que as secreções corporais podem ser consideradas menos ou mais ofensivas a depender do grupo social, foi possível apreender que o suor influenciava os alunos nos seus anseios para o corpo em função dos contextos socioeconômicos e culturais, como poderá ser visto a seguir.

\section{Academia P: "Venha suar a camisa"!}

No espaço da academia $\mathrm{P}$, era impossível não transpirar. O estabelecimento quase não possuía telhado (o que é denominado de "laje") e não possuía sistema de climatização de ar condicionado. Os alunos frequentavam o local ou se exercitavam exaustivamente até saírem "pingando", ou seja, o próprio espaço desse estabelecimento propiciava situações-limite aos seus alunos como, por exemplo, os corpos no "limite" do suor. Para os alunos, essas situações-limite eram vistas positivamente sempre se referindo que "já estavam acostumados" com as altas temperaturas ou que "era assim que ficava bom" para se exercitar. Os alunos rotineiramente se remetiam a tais circunstâncias de temperatura e do local relacionando ao suor:

Marcinho: "A galera que está aqui quer ganhar massa muscular. Para quem quer emagrecer, essa telha de amianto é ótima, porque é assim, ao longo do dia ela absorve o calor e lá para o finalzinho da tarde isso aqui continua bem quente pra galera suar".

Tigrão: "Só pra tu ver, o calor de hoje me fez aumentar cinco quilos naquele aparelho e dez quilos aqui! Hoje eu vou crescer"!

Aristides: "Só maluco quer malhar com sol. Esse tempo meio frio que é bom! Maluco é achar que pra ter resultado tem que perder líquido, o que eu quero é ganhar"!

As noções de "quente" e de "frio", ligadas ao ato de suar, transitavam entre o "perder" e o "ganhar" corpo. Havia uma tendência do gosto dos alunos da academia P pelo quente do que pelo frio, o que era visível na representação do suor que propiciaria benefícios ao corpo. A eficácia dos exercícios físicos somente seria atingida se o suor emergisse da pele de forma significativa, isto é, quanto mais suor, maior era o efeito positivo das práticas corporais. Para Helman (1994, p.37), 
muitas vezes, há a crença de que "A saúde pode ser mantida ou perdida pelo calor ou pelo frio do corpo $[\ldots] "$.

Grande parte dos alunos tinha aversão aos poucos ventiladores que ajudavam a circular o ar naquele espaço. Eles afirmavam que a ventilação prejudicava a malhação deles. Alguns queriam perder peso, logo suavam para emagrecer. Outros desejavam ganhar massa muscular e a temperatura quente do músculo auxiliaria nesse processo:

Sheik: "Porra, ventilador ligado de novo? Desliga essa porra! Aí, cambada, estou desligando tudo! Vocês querem sentir frio"?

Michael: "É bom malhar no calor mesmo"!

Lucas: "Sua mais, sinto mais o corpo, é bom pra secar"!

Sheik: "Você é instrutor de Educação Física, você sabe, se o músculo esfria, ele fica contraído e daí não cresce. Se ele estiver quente, ele fica bombando lá dentro, daí ele cresce! Por isso, desligo todos os ventiladores quando chego"!

Confirmando o valor dado às altas temperaturas no ambiente, relatos dos alunos sobre isso eram frequentes. Uma aluna, por exemplo, referiu que embora a academia estivesse em condições precárias de uso, não sairia dali porque os outros locais de práticas corporais das redondezas tinham ar condicionado; para ela, era inimaginável malhar com ar condicionado, pois o suor não iria aparecer. Outro aluno declarou que para quem desejava emagrecer, a opção de malhar ao ar livre era ótima, mas com o ar condicionado o músculo ficaria contraído demais; “doido" era aquele que gostava de malhar em um ambiente climatizado com ar condicionado porque não suava; ele afirmava que também não suportava o ventilador. Outra aluna me contava que mesmo a prima dela a chamando para malhar em uma academia com ar condicionado, não iria, porque um lugar frio não deixaria o suor sair da pele e que isso a deixaria "melada", mas não "molhada" como tão desejava.

As roupas usadas pelos alunos eram de algodão em vez de tecidos dry-fit (comum na academia G). Essa opção era tanto pela dimensão do custo, mas também pela ordem simbólica do suor. Alguns alunos levavam calças (muitas delas de tecidos jeans) e casacos para se exercitar, mesmo que a temperatura do dia estivesse em torno de trinta a quarenta graus. Helman (1994, p.32) destaca que "A adequação aos padrões culturais não se dá apenas através da alteração das formas do corpo, mas também do uso de determinadas roupas [...]".

Ademais, preferiam determinados exercícios físicos a outros, hierarquizando a escolha de práticas corporais com maior ou menor capacidade de elevar a transpiração. Optavam, por exemplo, por aparelhos de musculação que ficavam mais localizados onde a academia recebia a luz solar ou aqueles exercícios físicos que mobilizavam maior número de grupamentos musculares.

Os praticantes de musculação não ficavam parados por muito tempo, porque havia a crença de que o músculo iria relaxar e descansar. Um músculo frio não produziria benefícios ao corpo, 
enquanto um músculo quente, em plena produtividade vista pelo suor dos corpos, era almejado frequentemente. Dessa maneira, no momento em que alguns alunos ficavam conversando entre a realização dos exercícios físicos, eram cobrados por outros para suarem com provocações do tipo: “Isso aqui não é botequim, é pra malhar, é pra suar!”, "Está malhando gogó? Por isso que não cresce, já esfriou!”, “Se demorar muito, não vai conseguir suar, vai rápido e usa logo o aparelho, sai da conversa, bater-papo é na pracinha!”, etc.

Em termos gerais, no ponto de vista dos pesquisados da academia $\mathrm{P}$, o frio não fazia o corpo suar e por isso não era viável para quem desejava perder gordura ou ganhar massa muscular. O próprio antropólogo Malysse (2008) em seu diário de campo relata no seu estudo que a todo instante sentia os "efeitos" do exercício físico nos momentos em que suava. Em contrapartida, para raros alunos, tal temperatura era propícia para o ganho de massa muscular na medida em que conservaria toda a estrutura corporal, sendo assim, quem gostaria de "crescer" corporalmente perdia menos massa muscular em dias mais frios.

Muitas vezes, tais representações ultrapassavam o âmbito das práticas corporais. Isso podia ser visto quando o suor era associado à relação entre a vida "atlética" dentro da academia e à vida do "trabalho" fora da mesma:

Kiko: "Quando você trabalhava, eu já malhava há três anos aqui, eu tenho tanta moral aqui que posso até malhar descalço se eu quiser.

Tigrão: Mentira! Eu já carregava saco de cimento, quando você ainda brincava de boneco. Eu suava bem antes de você aqui, beleza"?

Edilson: "Vê se pode, trabalho desde às três da manhã direto, só paro pra malhar e volto. Tem gente que não faz porra nenhuma e não cresce e nem faz a metade do que eu trabalho, suo lá e aqui, e ainda dizem que eu me pico de anabolizante, é trabalho isso"!

Assim, embora alguns estudos apontem que as classes populares se atentam, se preocupam ou consomem igualmente padrões de beleza valorizados pelas camadas sociais mais privilegiadas (FERREIRA; MAGALHÃES, 2006; BRAGA; MOLINA; FIGUEREIDO, 2010), notava que tais ideais supostamente mais legítimos possuíam referências singulares no contexto da CDD. A massificação das aparências que atravessam classes sociais (VIGARELLO, 2006; LIPOVETSTKY, 2009) ou as próprias atitudes e costumes em geral que seriam moldados “de cima para baixo" em um processo civilizador (ELIAS, 1994), devem ser relativizadas à luz de determinados contextos e grupos sociais. Em outras palavras, o suor era também de quem trabalhava e não apenas de quem praticava exercícios físicos no "limite". 
Os profissionais da academia $\mathrm{P}$ costumavam estimular a transpiração dos alunos. Uma malhação "boa" em termos de prescrição de exercícios físicos seria aquela que traria o "suor" para a pele dos frequentadores:

Prof. José: "Hoje de manhã fiz uma série boa pra mim, você tinha que ver, o músculo ficou quente e duro, suei de verdade"!

$\mathrm{Eu}$ : "Como foi a série"?

Prof. José: “Assim, eu sentei aqui na cadeira extensora e fiz quinze repetições, mas no final de cada de repetição eu ficava sustentando o peso no ângulo mais difícil, muito bom, a perna ficou inchada. Os alunos vieram tocar na minha coxa e ficaram surpresos como estava quente e duro. A malhação de hoje foi muito boa, a galera me viu suar"!

Eu: "A galera fala por aí que você emagrece geral"!

Prof. Cobra: "É, eu consigo emagrecer as pessoas porque sei como secar elas, eu consigo, por exemplo, emagrecer dezoito quilos em um mês".

Eu: "Caramba, tudo isso? Aquele ali é um aluno seu"?

Prof. Cobra: "É sim, volta e meia você vai ver ele caindo por aí! Ele sua demais, desidrato ele legal! Pode ver que ele já está com o "olho fundo"! O pessoal gosta de mim porque acabo com geral, quem tá malhando é pra se molhar"!

O professor de Educação Física da academia P ao valorizar o suor se alinhava a perspectiva dos frequentadores que ali se exercitavam em "plena e contínua transpiração". Embora teoricamente o profissional estivesse munido dos saberes fisiológicos relativos à transpiração e à hidratação, a atuação profissional tendia a incentivar o ato de suar. Dessa forma, o professor potencializava sua legitimidade profissional diante dos alunos. O suor dos alunos seria um dos dados mais concretos que suas orientações relativas às práticas corporais estavam adequadas e deveriam ser seguidas por aqueles que ali se exercitavam. Era recorrente ver os professores cobrando, criticando ou parabenizando seus alunos pela quantidade de suor que estavam expondo no corpo, pois, somente assim, alcançariam os seus resultados no estabelecimento.

Dessa maneira, o professor de Educação Física naturalizava o suor no extremo "limite" dos esforços físicos dos frequentadores. Aquele profissional que, porventura, não exigisse dos seus alunos a visibilidade do suor, não tinha tanta credibilidade quando comparado ao outro professor que estimulava o ato de transpirar. Tais representações eram notórias entre os alunos:

Diva: "Eu gosto de ser estimulada, entendeu? Por exemplo, eu sei que não tem muito a ver, mas gosto do professor que quer me ver suar".

Katiucia: "A orientação da professora Eliana que mais me emagreceu, é a melhor, ela é boa demais! Eu saio daqui pin-gan-do de suor com ela e sabe o que ela faz? Ela grita com a gente, ela é má, sinto várias dores na aula dela, ela é a professora melhor daqui, ela é nota mil"! 
Desse modo, parte do lugar social do profissional na academia $\mathrm{P}$ se derivava circunstancialmente do que ou quanto poderia "oferecer de suor" aos seus alunos. Assim, na maioria das vezes, profissionais e alunos compartilhavam semelhantemente a carga simbólica do suor. Pouquíssimos eram aqueles frequentadores que tinham aversão à essa secreção, procurando o desinfetante espalhado pela musculação para eliminar o suor dos equipamentos ou trazendo toalhas de casa para se enxugarem enquanto se exercitavam.

A própria administração da academia $\mathrm{P}$ incorporava tal representação do suor. Em "chamadas" do estabelecimento para aulas que iriam inaugurar ou acontecer, vinha escrito no seguinte sentido: "A academia de ginástica $\mathrm{P}$ convida todos os alunos para participar da nossa aula de preparação Power Fight. Benefícios: 'perca' de gordura localizada, resistência, ganho de força, definição e condicionamento físico. Venha suar a camisa!”. O estabelecimento compartilhava de tal representação acerca do ato de suar, pois o objetivo das práticas corporais seria transpirar a todo custo. Logo, um dos artifícios para o lucro da academia P também era atravessado por essa secreção corporal.

\section{Academia G: "Sue, porém nem tanto"!}

Já na academia da Barra, as noções de suor eram diferentes daquelas vistas na academia da CDD. O ambiente da academia $\mathrm{G}$ era climatizado pelo amplo sistema de ar condicionado. Caso esse sistema de climatização não estivesse funcionando adequadamente ou se os alunos estivessem fadigados, os relatos convergiam para a aversão ao suor:

\footnotetext{
Jéssica: "Que suor é este em você"?

Glória: "Que isso, menino"?

Robert: "É, pois é, tenho que descolar a camisa do corpo, vou segurar para não ficar grudando".

Euclides: "Vamos para o outro exercício"!

Nilton: "Calma aí, estou tirando o suor aqui, bicho! Tá forte o negócio"!

Everaldo: "Depois daqui, vamos passar ali".

Iverson: "Mas eu vou assim? Suado que nem um porco? Nem pensar"!

Diego: "Cara, eu tenho nojo do cheiro de suor, aquilo fica preso em mim, mesmo com ar condicionado, não consigo".

Átila: "Eu também tenho".
}

Grande parte dos alunos preferia o frio ao quente, principalmente porque o suor atrapalharia a sociabilidade tão valorizada naquele espaço. Quando alguns alunos começavam a transpirar em qualquer espaço da musculação, tinham o cuidado de não deixar os aparelhos molhados de suor e de 
ser estigmatizados no local. Utilizando-me das palavras de Ory (2008), parecia que naquele estabelecimento havia uma espécie de "desodorização corporal", haja vista que eliminar qualquer indício do suor era uma prática comum entre aqueles que frequentavam o espaço da academia G. Com efeito, uma das perspectivas de Douglas (1991) que os fluidos são mais tolerados pelas pessoas dentro do corpo e quando se estão fora ameaçam moralmente o sujeito parecia preponderar no estabelecimento da Barra. Rotineiramente, havia relações jocosas tais como "Tá chovendo lá fora?" ou “Tomou banho de camisa?", demonstrando o quão perturbador era suar na academia G. O suor ali como "impureza" não estava associado apenas a uma questão de higiene, de etiqueta, de estética ou de conhecimento dos organismos patogênicos, mas um elemento potencialmente destruidor dos arranjos ou da ordem social (DOUGLAS, 1991).

$\mathrm{Na}$ academia $\mathrm{G}$, os alunos eram mal vistos caso não estivessem usando roupas que evitassem o suor. A única tolerância para as camisetas de algodão era se elas fossem de determinada marca/grife. A opção pela moda de vestuário fitness ou sportwear se concretizava nas discussões cotidianas entre os alunos, isto é, tais materiais já se referiam ao dry-fit "contra o suor". Esses dados vão ao encontro da ideia de Douglas (1991, p.76) quando lembra que "Todas as nossas roupas, todos os nossos alimentos, de facto todos os nossos objectos usuais, não passam de adereços de teatro que nos permitem precisar a maneira como queremos representar os nossos papéis e a cena que representamos".

Além disso, os alunos da academia G raramente elaboravam uma associação direta entre o ato de transpirar e os efeitos das práticas corporais. Eles entendiam que se o treino estivesse sendo realizado de modo "correto", a manutenção da massa muscular e a eliminação de gorduras aconteceriam "naturalmente". Embora alguns profissionais de Educação Física comentassem que os alunos dali eram mais informados e por isso poucos eram aqueles que acreditavam na necessidade de suar para terem algum efeito do exercício físico, observava que não era apenas uma questão de saber "mais" ou "menos", mas de não desejar sentir tal secreção corporal. Na perspectiva de Bourdieu (1983a, p.152), “As funções higiênicas tendem cada vez mais a se associar, e mesmo a se subordinar, a funções que se pode chamar de estéticas, à medida que se sobe na hierarquia social".

Os próprios professores de Educação Física da academia G contribuíam para a representação de que o ato de suar era uma situação que afetava moralmente os sujeitos, reforçando a ideia pejorativa de nojo de tal secreção corporal:

Prof. Reginaldo: "Oi, tudo bem? Está suando muito, hein"?

Frederico: "Estou sim, horrível"!

Prof. Reginaldo: "Quer uma sugestão? Troca essa camisa e bota outra, daí, quando você começar a suar, você vai no banheiro e troca até terminar os seus exercícios aqui". 
Frederico: "Boa ideia"!

Prof . Suzana: "Esse exercício é pra você ir pra guerra"!

Ticiane: "Ah, não, ufa, esteira de novo"?

Profa. Suzana: "Sim, vou pegar o papel, você tá suando"!

Os profissionais de Educação Física, no ponto de vista de Fensterseifer e Silva (2008), são vistos, muitas vezes, como "missionários do suor" no sentido de deterem o poder de penitenciar aqueles considerados distantes das condutas corporais que levariam ao aprimoramento de si. Os mesmos também mantinham a noção de suor como algo depreciativo. $\mathrm{O}$ aluno deveria se exercitar no "limite" até alcançar níveis ideais de suor, mas com total discrição e de controle rígido dessa secreção corporal, isto é, “sue, porém nem tanto!".

Entretanto, em algumas situações, o professor de Educação Física da academia G impunha a autoridade ao seu aluno no sentido de cultuar e ressignificar o suor em prol da desidratação em si. Cheguei a observar, por exemplo, um profissional que durante uma hora proibia a aluna de beber água, mesmo esta implorando a cada conjunto de exercícios físicos que precisava se hidratar porque estava suando demasiadamente. Presenciei também outro professor que negava frequentemente a solicitação de um corpo de água da sua aluna: “Ah, fala sério! Aluna minha não bebe água, ela sua!". Destarte, os profissionais reforçavam o que Courtine (1995) denomina de "tecnologia do suor", isto é, a clássica representação da ideia de garantia de mudar o corpo apenas pelo próprio sacrifício de se exercitar.

Muitos profissionais confessavam que a depender do "quanto de suor" havia sobre a pele do outro, tinham repulsa de tocar na "pele molhada". Já outros professores consideravam essa situação inerente ao trabalho e, por vezes, eram a favor da hidratação constante:

Prof. Régis: "Vou te falar, tenho nojo de suor de aluno. Por exemplo, tem aluno que não tem bom senso. $\mathrm{O}$ aluno pede para eu alongar com as roupas totalmente encharcadas".

Prof. Gilmar: "Os alunos ficam putos quando estão correndo e pedem nas prescrições para não suar, inclusive você pode ver, toda hora tem um querendo que aumente o ar condicionado. Eu acho isso um absurdo, o suor serve para manter a temperatura corporal, dentre outros benefícios. É preciso se hidratar e ponto! Eu só peço para não me tocarem"!

Prof. Osiris: "Cara, isso é muito constrangedor. Já vi aluno que pelo fato de suar no aeróbio, tomava banho e depois retornava para fazer os exercícios na musculação. Acho que é até uma coisa de higiene, mas as pessoas ficam olhando na cara de pau para quem tá suado. Teve um aluno que foi convidado para se retirar do local, o dono pediu para atendente não renovar a matrícula do cara, pois, ele quebrava os aparelhos do aeróbio. Esse aluno suava tanto que quebrou uns três transports da academia porque o suor estragava os mecanismos do aparelho". 
Cabe ressaltar que os cartazes de marketing divulgados e expostos no interior do estabelecimento faziam alusão à ideia de exercício físico sem sofrimento e sem suor como, por exemplo, chamadas do tipo: "Você não pode ficar de fora da maratona da academia de ginástica 'G'! Serão 2 horas de ginástica localizada numa aula super especial preparada com todo carinho para você na quadra" (cartaz acompanhado de uma foto em cor de rosa de uma mulher jovem branca fazendo abdominal e os patrocinadores ao lado); “Calendário de corridas da academia de ginástica ' $\mathrm{G}$ ', participe! Desafio de running! O vencedor ganhará um pacote de corrida para o exterior e um kit da loja ' $\mathrm{X}$ '. Tem que correr 45 minutos e a maior distância ganha" (cartaz mostrando um homem jovem branco correndo e sorrindo sem expressão de cansaço).

Em termos gerais, havia pouco interesse dos alunos em se exercitar de forma duradoura e intensa na musculação em busca de corpos suados. Geralmente, essa referência de um "corpo rústico" se atrela, em parte, a ideia do corpo operário que é um corpo trabalhado ou do trabalhador (CORBIN, 2009). Por isso, como uma forma de distinção, na academia G, parecia que o modelo slim de corpo era mais privilegiado, porém de forma mais "seca" possível e menos "sacrificado". Assim, era possível observar justamente o que Bourdieu (1983a) discutia sobre o "campo esportivo": enquanto, por exemplo, antigamente o halterofilismo era mais valorizado pela camada popular pela visibilidade das carnes e dos músculos, o modelo de corpo delgado do golfe era privilegiado pela elite. Bourdieu (1983) afirma também que essa própria estética é apreciada de forma diferente entre as classes sociais e em diferentes capitais culturais.

\section{CONSIDERAÇÕES FINAIS}

Não raro o Rio de Janeiro é uma das cidades brasileiras associada a determinados estereótipos, relativos à valorização do corpo "musculoso, sensual, simpático, descolado, etc". Embora no senso comum essas ideias de corpos do Rio de Janeiro fiquem geralmente associadas ao contexto litorâneo da zona sul ou de áreas mais nobres da cidade, vale ressaltar que no interior da mesma cidade há outras formas - leia-se populares - de expressar esses corpos, como aqueles tidos como rústicos, grandes, suados, sofridos, resistentes, fortes, trabalhadores ou operários, etc. Esses últimos corpos também são característicos da cidade, mas raramente aparecem na mídia ou em campanhas de publicidade.

Em síntese, na academia $\mathrm{P}$, havia a valorização do ato de suar e das temperaturas quentes ligadas à ideia de ganhos de massa muscular e de eliminação de gorduras. Na academia G, o suor tendia a ser evitado por ser considerado um elemento moralmente depreciativo ao sujeito, por isso a 
transpiração raramente era indicada como um indício de performance nas práticas corporais, predominando, assim, o interesse pelas temperaturas frias.

Longe de polarizar ou essencializar os achados, foi possível perceber que as representações sobre o suor na musculação em academias podiam variar entre e nos mesmos grupos sociais. Entretanto foi possível observar certa regularidade nas concepções dos alunos de acordo com suas condições socioeconômicas e culturais acerca do suor e sua relação com os seus anseios para o corpo.

Logo, o presente trabalho etnográfico comparativo estabeleceu relações entre as representações de suor e suas expectativas de beleza e saúde. Isso permite pensar como os profissionais de Educação Física podem interagir com seus alunos nas academias de forma a corresponder aos seus anseios e expectativas. Assim, os dados dessa pesquisa fornecessem indícios de que a forma como engajam, interagem ou se mantêm nas práticas corporais não somente revelam as inserções sociais dos praticantes, como também ajudam o profissional a entender e atuar com o Outro. Nesse sentido, as representações sobre o suor tornam-se um dos elementos-chaves para aqueles que desejam atuar de modo mais humanizado e menos tecnocrático com as pessoas que se exercitam já que não os concebem apenas como "corpos objetos" ou meramente em seus aspectos físicos, mas, sobretudo, como "corpos-sujeitos".

Portanto, nesse contexto comparativo de distinção entre os grupos sociais dos estabelecimentos, é possível entender que "Lavar pode ser muito mais que prática instrumental de limpeza, cuidado e preservação da saúde: pode também ser mecanismo simbólico inconsciente para separar domínios e estabelecer relações." (ROCHA; RODRIGUES, s/d, p.21), dado este importante a ser apreendido e compartilhado tanto na produção de saberes quanto nas práticas de intervenção da/ na área de Educação Física que a todo instante lida com “corpos suados”.

\section{REFERÊNCIAS}

BERTEVELLO, Gilberto. Academias de ginástica e condicionamento físico: sindicatos \& associações. In: DaCOSTA, Lamartine (Org.). Atlas do esporte no Brasil. Rio de Janeiro: CONFEF; 2006. p. 65-66.

BOLTANSKI, Luc. As classes sociais e o corpo. 3. ed., São Paulo: Paz e Terra, 2004.

BOURDIEU, Pierre. Sociologia. São Paulo: Ática, 1983.

BOURDIEU, Pierre. Questões de sociologia. Rio de Janeiro: Marco Zero, 1983a. 
BRAGA, Patrícia Déa; MOLINA, Maria del Carmen Bisi; FIGUEIREDO, Túlio Alberto Martins. Representações do corpo: com a palavra um grupo de adolescentes de classes populares. Ciência \& Saúde Coletiva, Rio de Janeiro, v. 15, n. 1, p. 87-95, 2010.

CORBIN, Alain. Dores, sofrimentos e misérias do corpo. In: CORBIN, Alain; COURTINE, JeanJacques; VIGARELLO, Georges (Org.). História do corpo: da revolução à grande guerra. 3. ed., Petrópolis: Vozes, 2009. p. 267-343.

COURTINE, Jean-Jacques. Os stakhanovistas do narcisismo: body-building e puritanismo ostentatório na cultura americana do corpo. In: SANT'ANNA, Denise Bernuzzi. (Org.) Políticas do corpo. 2. ed., São Paulo: Estação Liberdade, 1995. p. 39-48.

DaMATTA, Roberto. Relativizando: uma introdução à antropologia social. Rio de Janeiro: Rocco, 2010.

DOUGLAS, Mary. Pureza e perigo: ensaio sobre a noção de poluição e tabu. Rio de Janeiro: Ed. 70, 1991.

ELIAS, Norbert. O processo civilizador: uma história dos costumes. 2. ed., Rio de Janeiro: Zahar, 1994.

FENSTERSEIFER, Paulo Evaldo; SILVA, Sidinei Pithan. Qualidade de vida e Educação Física: conhecimento e intervenção crítica na sociedade de consumo. Cadernos de Educação Física (UNIOESTE), Marechal Cândido Rondon, v. 7, n. 12, p. 55-58, 2008.

FERREIRA, Vanessa Alves; MAGALHÃES, Rosana. O corpo cúmplice da vida: considerações a partir dos depoimentos de mulheres obesas de uma favela carioca. Ciência \& Saúde Coletiva, Rio de Janeiro, v. 11, n. 2, p. 483-490, 2006.

FURTADO, Roberto Pereira. Do fitness ao wellness: os três estágios de desenvolvimento das academias de ginástica. Pensar a Prática, Goiânia, v. 12, n. 1, p. 1-11, jan./abr. 2009.

HANSEN, Roger; VAZ, Alexandre Fernandez. Treino, culto e embelezamento do corpo: um estudo em academias de ginástica e musculação. Revista Brasileira de Ciências do Esporte, Campinas, v. 26, n. 1, p. 135-152, set. 2004.

HELMAN, Cecil. Cultura, saúde e doença. 2. ed., Porto Alegre: Artes Médicas, 1994.

LE BRETON, David. La sociologie du corps. Paris: Puf, 2016.

LIPOVETSKY, Gilles. O império do efêmero: a moda e seu destino nas sociedades modernas. São Paulo: Companhia das Letras, 2009.

MALINOWSKI, Bronislaw. Introdução: o assunto, o método e o objetivo desta investigação. In: DURHAM, Eunice Ribeiro (Org.) Malinowski. São Paulo: Ática, 1986. p. 24-48.

MALYSSE, Stéphane. Em busca dos (h)alteres-ego: olhares franceses nos bastidores da corpolatria carioca. In: GOLDENBERG, Mirian. (Org.) Nu \& Vestido: dez antropólogos revelam a cultura do corpo carioca. 2. ed., Rio de Janeiro: Record, 2007. p. 79-137. 
MALYSSE, Stéphane. Diário acadêmico. São Paulo: Estação das Letras e Cores, 2008.

MINAYO, Maria Cecília de Souza. O desafio do conhecimento: pesquisa qualitativa em saúde. 12. ed., São Paulo: Hucitec, 2010.

ORY, Pascal. O corpo ordinário. In: CORBIN, Alain; COURTINE, Jean-Jacques; VIGARELLO, Georges (Org.). História do corpo 3. As mutações do olhar: o século XX. Petrópolis: Vozes, 2008. p. 155-195.

ROCHA, Everardo; RODRIGUES, José Carlos. Corpo e consumo: roteiro de estudos e pesquisas. Rio de Janeiro: PUC/RJ, s/d.

RODRIGUES, José Carlos. Tabu do corpo. 7. ed., Rio de Janeiro: Ed. Fiocruz, 2006.

SASSATELLI, Roberta. Interaction order and beyond: a field analysis of body culture within fitness gyms. In: FEATHERSTONE, Mike (Ed.). Body modification. London: Sage, 2000. p. 227248.

SILVA, Alan Camargo. Limites corporais e risco à saúde na musculação: etnografia comparativa entre duas academias de ginástica cariocas. 2014. Tese (Doutorado em Saúde Coletiva) - Instituto de Estudos em Saúde Coletiva, Universidade Federal do Rio de Janeiro, Rio de Janeiro, 2014.

SILVA, Alan Camargo. Da Antropologia da Saúde para Educação Física: práticas corporais sob análise. In: TELLES, Silvio; LÜDORF, Sílvia Maria Agatti; PEREIRA, Erik. (Org.). Pesquisa em

Educação Física: perspectivas sociocultural e pedagógica em foco. Rio de Janeiro: Autografia, 2017. p. 50-57.

VELHO, Gilberto. Antropologia urbana: encontro de tradições e novas perspectivas. Sociologia, Problemas e Práticas, Lisboa, n. 59, p. 11-18, 2009.

VIGARELLO, Georges. História da beleza: o corpo e a arte de se embelezar, do renascimento aos dias de hoje. Rio de Janeiro: Ediouro, 2006.

\section{NOTAS DE AUTOR}

\section{AGRADECIMENTOS}

Não se aplica.

\section{CONTRIBUIÇÃO DE AUTORIA}

Não se aplica.

FINANCIAMENTO

Não se aplica.

CONSENTIMENTO DE USO DE IMAGEM

Não se aplica.

\section{APROVAÇÃO DE COMITÊ DE ÉTICA EM PESQUISA}


Esta pesquisa foi aprovada e autorizada pelo Comitê de Ética em Pesquisa do Instituto de Estudos em Saúde Coletiva da Universidade Federal do Rio de Janeiro (CAAE: 01559712.7.0000.5286 / Número do parecer: 203.235).

\section{CONFLITO DE INTERESSES}

Não se aplica.

\section{LICENÇA DE USO}

Os autores cedem à Motrivivência - ISSN 2175-8042 os direitos exclusivos de primeira publicação, com o trabalho simultaneamente licenciado sob a Licença Creative Commons Attribution Non-Comercial ShareAlike (CC BY-NC SA) 4.0 International. Esta licença permite que terceiros remixem, adaptem e criem a partir do trabalho publicado, desde que para fins não comerciais, atribuindo o devido crédito de autoria e publicação inicial neste periódico desde que adotem a mesma licença, compartilhar igual. Os autores têm autorização para assumir contratos adicionais separadamente, para distribuição não exclusiva da versão do trabalho publicada neste periódico (ex.: publicar em repositório institucional, em site pessoal, publicar uma tradução, ou como capítulo de livro), com reconhecimento de autoria e publicação inicial neste periódico, desde que para fins não comerciais e compartilhar com a mesma licença.

\section{PUBLISHER}

Universidade Federal de Santa Catarina. Programa de Pós-Graduação em Educação Física. LaboMídia - Laboratório e Observatório da Mídia Esportiva. Publicado no Portal de Periódicos UFSC. As ideias expressadas neste artigo são de responsabilidade de seus autores, não representando, necessariamente, a opinião dos editores ou da universidade.

\section{EDITORES}

Mauricio Roberto da Silva, Giovani De Lorenzi Pires, Rogério Santos Pereira.

\section{HISTÓRICO}

Recebido em: 18 de Fevereiro de 2019.

Aprovado em: 16 de Agosto de 2019. 